\title{
Ecological adaptations influence the susceptibility of plants in the genus Zantedeschia to soft rot Pectobacterium spp.
}

Yelena Guttman 1,2, Janak Raj Joshi@ ${ }^{1,3}$, Nofar Chriker ${ }^{1,2}$, Nirmal Khadka ${ }^{1,2}$, Maya Kleiman $\mathbb{D}^{2}$, Noam Reznik2, Zunzheng $\mathrm{Wei}^{2}$, Zohar Kerem ${ }^{1}$ and Iris Yedidia $\mathbb{C}^{2}$

\begin{abstract}
Soft rot disease caused by Pectobacterium spp. is responsible for severe agricultural losses in potato, vegetables, and ornamentals. The genus Zantedeschia includes two botanical groups of tuberous ornamental flowers that are highly susceptible to the disease. Previous studies revealed that $Z$. aethiopica, a member of the section Zantedeschia, is significantly more resistant to Pectobacterium spp. than members of the same genus that belong to the section Aestivae. During early infection, we found different patterns of bacterial colonization on leaves of hosts belonging to the different sections. Similar patterns of bacterial colonization were observed on polydimethylsiloxane (PDMS) artificial inert replicas of leaf surfaces. The replicas confirmed the physical effect of leaf texture, in addition to a biochemical plant-bacterium interaction. The differential patterns may be associated with the greater roughness of the abaxial leaf surfaces of Aestivae group that have evolutionarily adapted to mountainous environments, as compared to Zantedeschia group species that have adapted to warm, marshy environments. Transverse leaf sections also revealed compact aerenchyma and reduced the total volume of leaf tissue air spaces in Aestivae members. Finally, an analysis of defense marker genes revealed differential expression patterns in response to infection, with significantly higher levels of lipoxygenase 2 (lox2) and phenylalanine ammonia lyase (pal) observed in the more resistant $Z$. aethiopica, suggesting greater activation of induced systemic resistance (ISR) mechanisms in this group. The use of Zantedeschia as a model plant sheds light on how natural ecological adaptations may underlay resistance to bacterial soft rot in cultivated agricultural environments.
\end{abstract}

\section{Introduction}

Zantedeschia, commonly known as calla lily, is one of the world's most iconic ornamental plants. It is endemic to southern Africa, but has been introduced worldwide as a cut flower, pot plant, garden, or landscape plant. The flower has been developed, for a variety of colors, mainly in New Zealand, the Netherlands, and the United States ${ }^{1}$. Zantedeschia is a genus of the Araceae family, with eight

\footnotetext{
Correspondence: Iris Yedidia (irisy@volcani.agri.gov.il)

${ }^{1}$ The Robert H. Smith Faculty of Agriculture, Food and Environment,

The Hebrew University of Jerusalem, Rehovot, Israel

${ }^{2}$ Institute of Plant Sciences, Agricultural Research Organization, Volcani Center, Rishon Lezion, Israel

Full list of author information is available at the end of the article

These authors contributed equally: Yelena Guttman, Janak Raj Joshi
}

species in two sections: section Zantedeschia with two white species ( $Z$. aethiopica Spreng. and $Z$. odorata Perry.) that flower during late winter/spring, with preference to warmer-temperature marshy habitats, and section Aestivae with six species of mostly colored, summer flowering callas that inhabit cool-temperature mountainous environments, and exhibit complete winter senescence (Z. albomaculata Baill., Z. elliottiana Engl., Z. jucunda Letty., Z. pentlandii Wittm., Z. rehmannii Engl., and $Z$. valida Singh $)^{2-4}$. Calla lilies are easily propagated through vegetative reproduction, yet, further horticultural development is limited due to high sensitivity to bacterial soft rot and virus infections ${ }^{5}$.

\section{(c) The Author(s) 2020}

(c) (i) Open Access This article is licensed under a Creative Commons Attribution 4.0 International License, which permits use, sharing, adaptation, distribution and reproduction c. in any medium or format, as long as you give appropriate credit to the original author(s) and the source, provide a link to the Creative Commons license, and indicate if changes were made. The images or other third party material in this article are included in the article's Creative Commons license, unless indicated otherwise in a credit line to the material. If material is not included in the article's Creative Commons license and your intended use is not permitted by statutory regulation or exceeds the permitted use, you will need to obtain permission directly from the copyright holder. To view a copy of this license, visit http://creativecommons.org/licenses/by/4.0/. 
Soft rot disease in Zantedeschia is caused mainly by Pectobacterium carotovorum, P. aroidearum, and Dickeya dadantii, former members of the Erwinia group ${ }^{6,7}$. $P$. brasiliense $(\mathrm{Pb})$ is an emerging pathogen in the family Pectobacteriaceae that has been reported in a wide range of hosts, including ornamental plants and vegetables such as Solanum tuberosum (potato), S. lycopersicum (tomato), and Cucumis sativus (cucumber) ${ }^{8}$. Pb tolerance to a wide range of temperatures, promoted its dispersal to different climate zones, from tropical regions such as Brazil to temperate regions such as Europe and North America ${ }^{9}$. Pectobacterium spp. are Gram-negative bacteria that utilize synchronized production of plant cell wall-degrading enzymes (PCWDEs) as their main virulence attribute $^{8,10,11}$, and enter the host through stomatal openings and wounds, colonize xylem vessels, parenchyma, and protoxylem cells ${ }^{12-14}$. Once temperature, humidity, and $\mathrm{pH}$ are suitable, the bacteria proliferate up to a critical number and start producing and secreting large amounts of PCWDEs that ultimately macerate the plant tissue ${ }^{15}$. They attack aboveground plants or underground storage organs, both in the field and in the warehouse, causing severe losses ${ }^{16}$.

Studies have characterized differences in the susceptibility of the two Zantedeschia sections to P. carotovorum infections $\mathrm{s}^{2-4}$. None have suggested a mechanism that underlies the observed variability. With no curative measures for the disease, integration of disease-resistant cultivars into breeding programs may become a viable tool to overcome the disease. However, although the evergreen $Z$. aethiopica is more resistant to Pectobacterium infection than the winter-dormant cultivars, the two groups cannot be crossed ${ }^{17,18}$. Interspecific hybrids suffer from plastome-genome incompatibility, producing degenerated, chlorophyll-deficient abnormal embryos $^{4,16,18}$.

Here, we have characterized morphological and biochemical differences that may explain the higher resistance of the section Zantedeschia to bacterial infection: anatomical differences and physical barriers that limit bacterial colonization, and immune response and activation of defense-related genes to combat bacteria ${ }^{19}$. These traits are suggested to result from the distinct ecological pressures, both biotic and abiotic, in the natural habitat of each Zantedeschia group. Ultimately, resolving the protecting features in the resistant Zantedeschia should open new paths for breeding toward increased tolerance and even resistance against soft rot disease.

\section{Results}

\section{Symptoms and biochemical reactions of infected} Zantedeschia varieties

Susceptibility of calla lilies to soft rot infection was studied using leaf disc assays, measuring the development of necrotic area following infection ${ }^{14,16}$. The results revealed significant variability in the progress of disease between white Zantedeschia (ZA), displaying less necrotic area and the commercial colored hybrids (Aestivae) "Florex Gold" (FG, yellow), "Captain Romance" (CR, pink), and "Hot Shot" (HS, orange) (Fig. 1A, B). CR, a colored representative hybrid, was used for infection assays with a GFP-labeled $P$. brasiliense strain $(\mathrm{Pb}+)$ that allowed monitoring bacterial colonization of tissues $24 \mathrm{~h}$ post inoculation. Confocal microscopy images revealed denser and more intense colonization around the inoculation site of $\mathrm{CR}$ in comparison to ZA. Moreover, using UV excitation, clear fluorescent rings around the bacterial penetration sites were observed in ZA but not in CR (Fig. $1 C)$. Such fluorescence is typical of the accumulation of phenolic compounds, during plant defense responses and is often accompanied by upregulation of oxidizing enzymes, mainly peroxidases (PODs) and polyphenol oxidases (PPOs). POD and PPO analysis in both Zantedeschia groups revealed higher basal levels of $\mathrm{POD}$ activity in CR, as compared with ZA (Supplementary Fig. $\mathrm{S} 1$ ); however, following infection with $\mathrm{Pb}$, POD activity was downregulated in $\mathrm{CR}$, while in $\mathrm{ZA}$, similar activity levels were observed in both treated and control samples. PPO activity increased significantly in ZA upon inoculation with $\mathrm{Pb}$ (Supplementary Fig. S1), and not in CR.

\section{Differential leaf morphology}

Transverse leaf sections of CR and ZA, representing the two calla lily groups, were stained with safranin-fast green and viewed under a light microscope. Lower tissue compactness and higher content of air spaces were observed in the mesophyll tissue of ZA than of CR (Fig. 2A). A similar pattern was observed in transverse petiole sections stained with toluidine blue (Fig. 2B). Quantitative determination of the accumulated air space per section area indicated far higher air-space volumes in leaves and petioles of ZA than of CR (Fig. 2C).

Adaxial (upper) and abaxial (lower) leaf surfaces were observed using a scanning electron microscope (SEM). The adaxial leaf surface was covered with a cuticle that was not different between ZA and CR. However, the abaxial surface of the leaves was clearly different between the two groups, displaying smooth surfaces for ZA and ridged rough pattern for $\mathrm{CR}$ (Fig. 2D).

\section{Bacterial colonization of leaf surfaces}

Bacterial colonization varied greatly between the two Zantedeschia cultivars, in line with the differences in leaf surface patterns. Dense colonization of Pectobacterium cells was observed on the abaxial leaf surface of CR using SEM, and only scattered cells on ZA (Fig. 3). Biofilm formation and exocellular polymers, observed in higher-resolution scans, followed the same trends. 


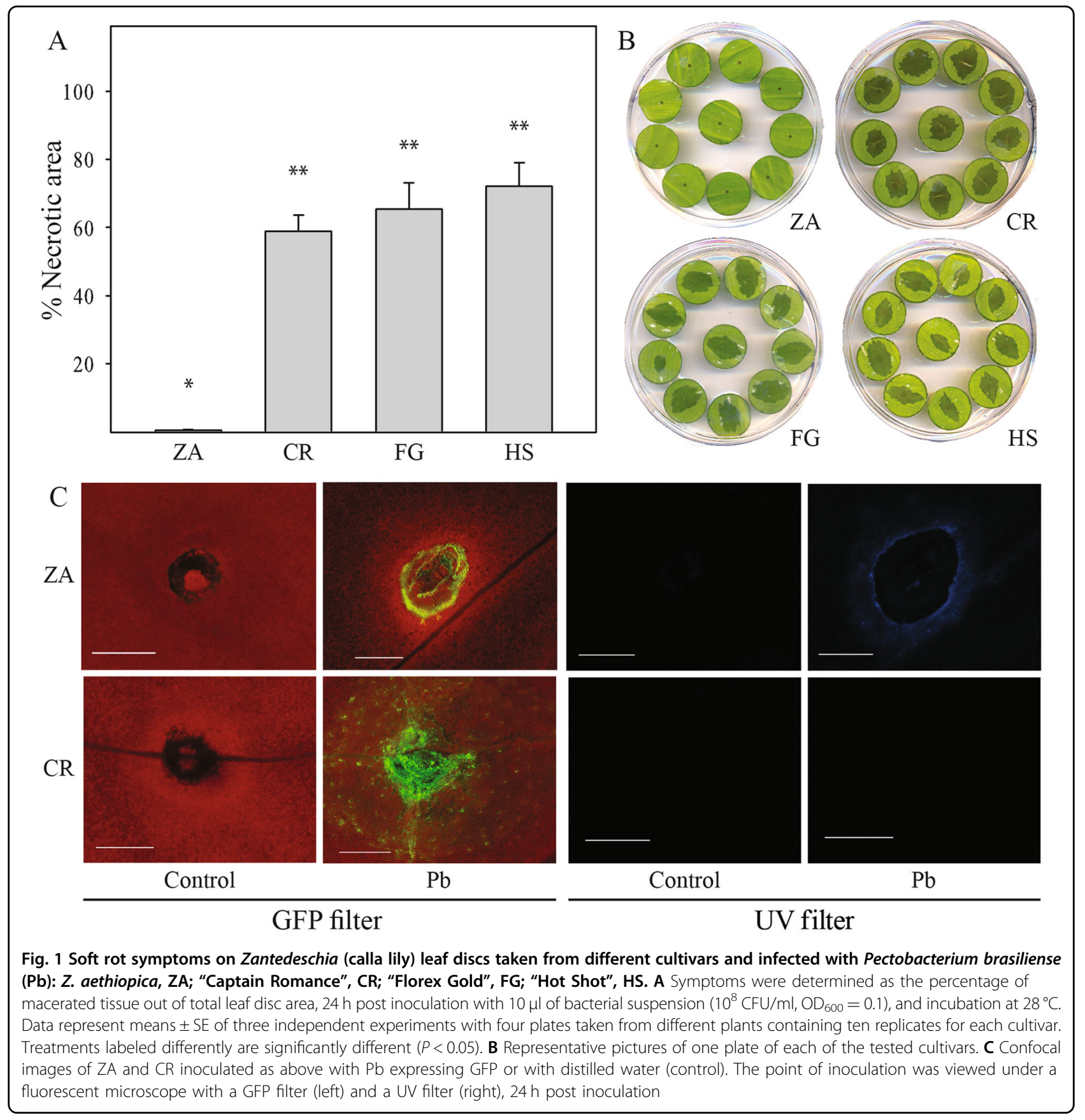

Submicrometer-scale appendages were observed on the leaf surface of the infected CR and not on ZA. Ridges and grooves, typical to the surface of the colored hybrids, supported bacterial establishment, with the orange hybrid HS being the most densely colonized.

To further test if differences in the pattern of the leaf surface could underlie group behavior and colonization by $\mathrm{Pb}$, artificial leaf surfaces were produced using siliconbased polymer PDMS, based on both ZA and CR. The artificial surfaces, chemically identical and structurally different, revealed distinctive colonization patterns that were strictly dependent on the architecture of the leaf surface. Three hours after $\mathrm{Pb}$ application to the surface, the smoother pattern of ZA was covered with bacterial cells that were apparently washed into lower topographic grooves on the surface. The bacterial cells were dispersed individually on the leaf plane (Fig. 4A-D); at the same time period, the artificial surface of CR, encouraged bacterial cell to attach and colonize the rigid, notched leaf plane already producing small cell clusters gathering into 


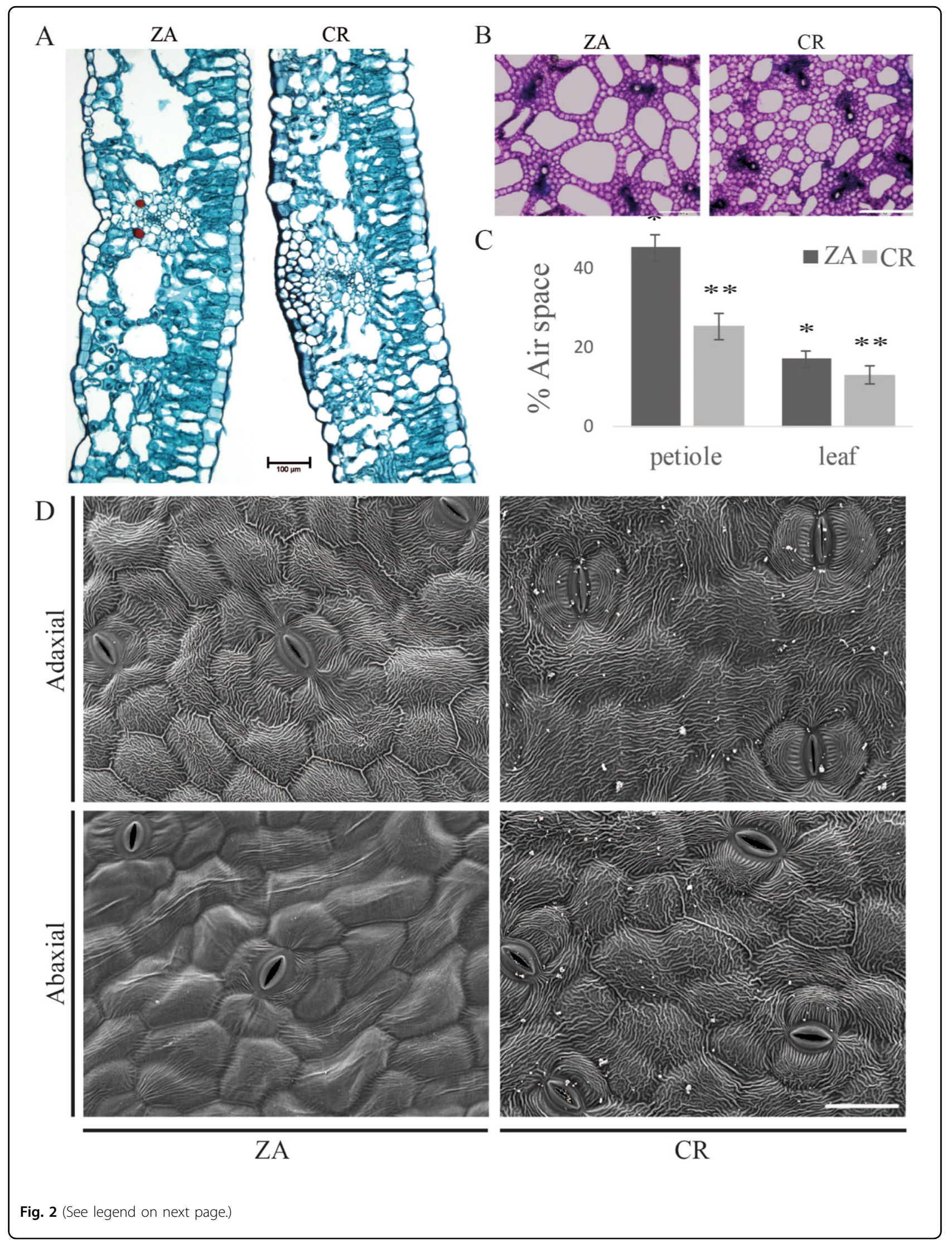


(see figure on previous page)

Fig. 2 Microscopic examination of leaf and petiole morphology of Zantedeschia aethiopica, (ZA) and the colored hybrid "Captain

Romance" (CR). A Transverse leaf section of ZA and the hybrid CR stained with safranin-fast-green viewed under a light microscope. Resolution $\times 10$, black bar $100 \mu \mathrm{m}$. B Transverse petiole section of ZA and the hybrid CR stained with toluidine blue and viewed under a light microscope. Resolution $\times 5$, white bar $500 \mu \mathrm{m}$. C Air-space ratio was calculated using ImageJ software, as a percentage of section area. Data represent means \pm SD of six fully opened second leaves. Treatments labeled with * are significantly different $(P<0.01)$. D Scanning electron microscopy (SEM) images of adaxial (upper) and abaxial (lower) leaf surfaces of ZA and CR. Resolution $\times 400$, white bar $50 \mu \mathrm{m}$

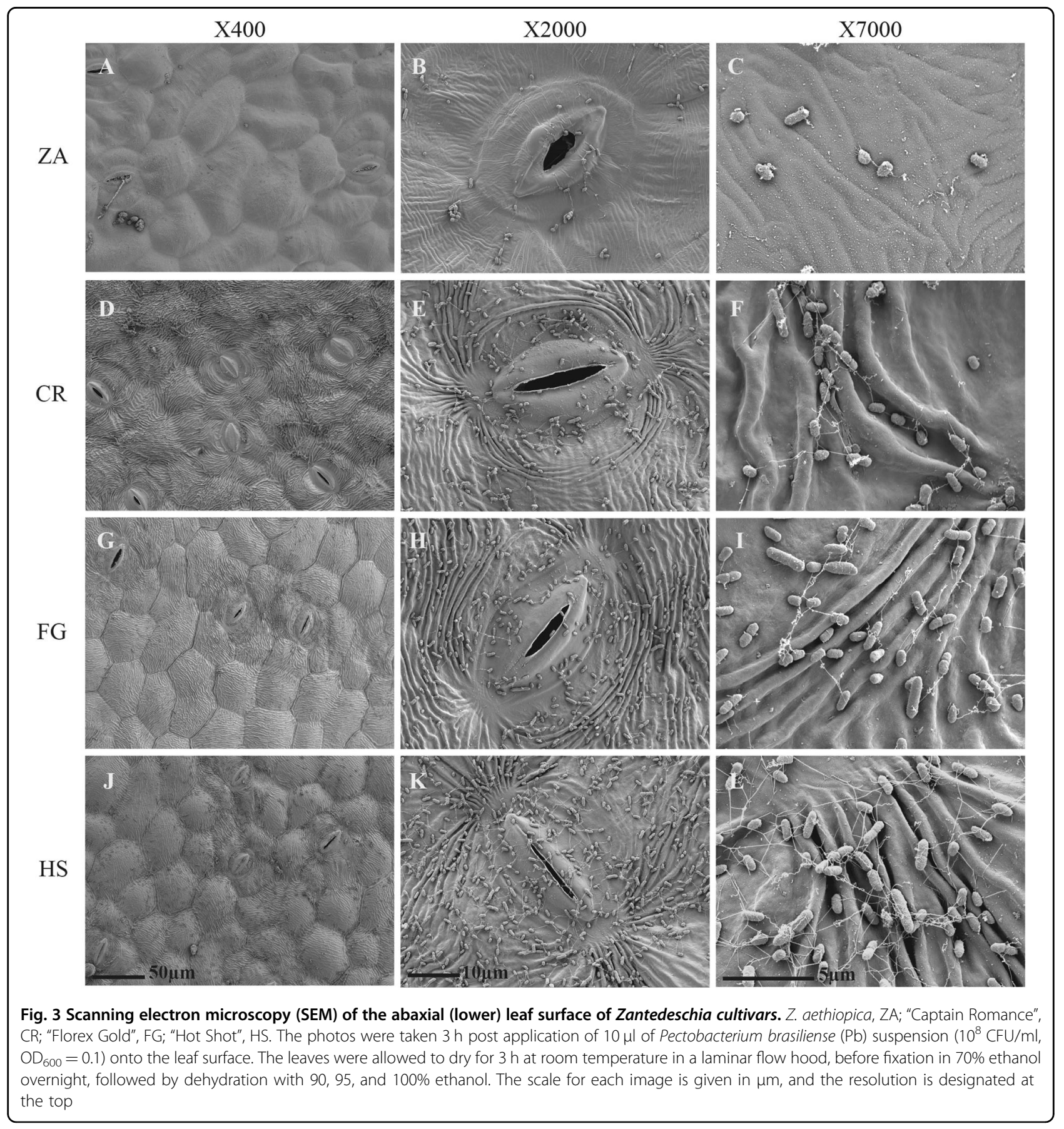




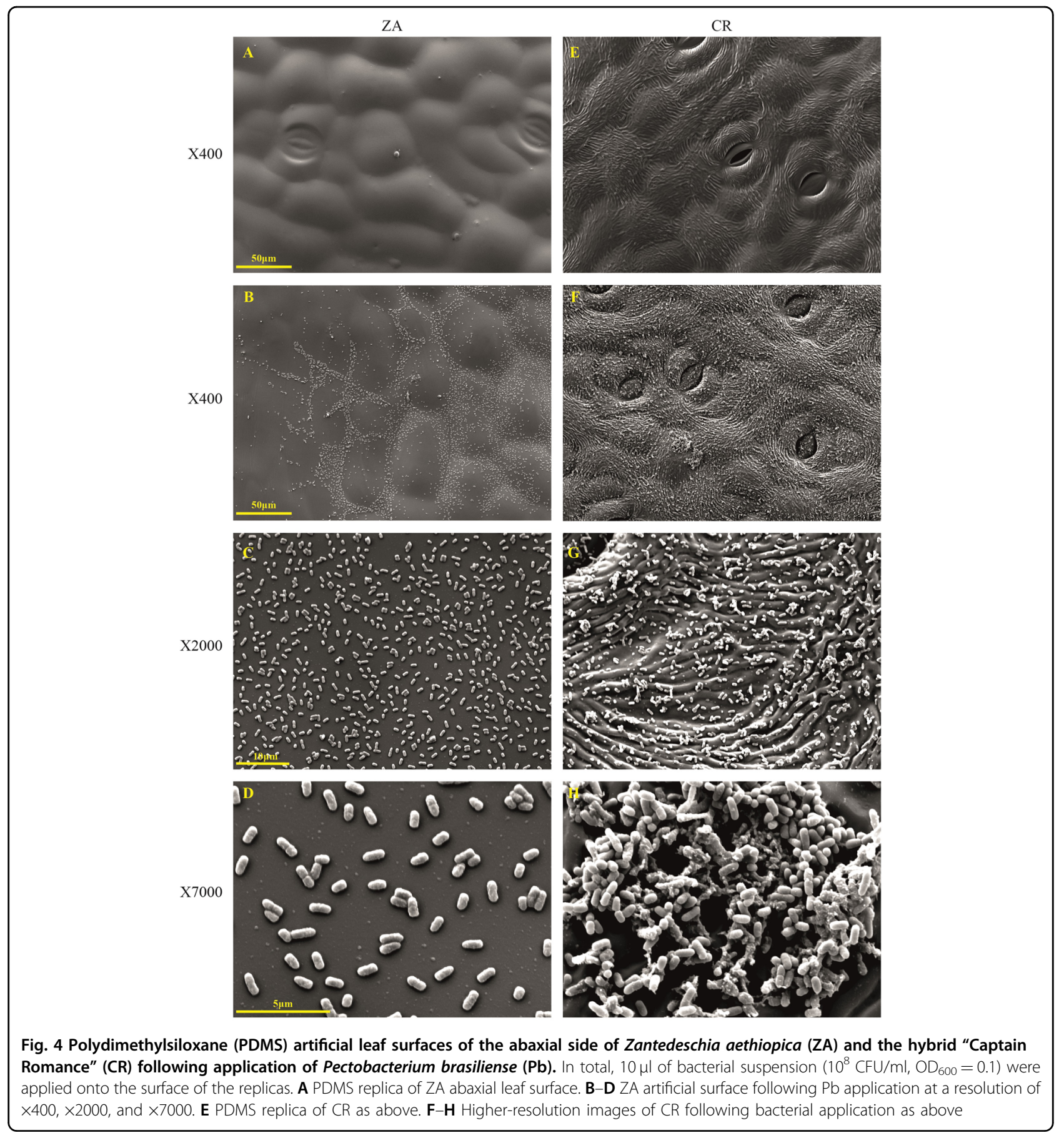

established biofilms (Fig. 4E-G), as observed by SEM at a higher resolution (Fig. 4H).

\section{Expression of plant defense-related genes}

Changes in the expression of representative plant defense genes were studied to further elucidate the difference in the response of $\mathrm{ZA}$ and $\mathrm{CR}$ to $\mathrm{Pb}$ inoculation (Fig. 5). Lipoxygenase 2 (lox2), phenylalanine ammonia lyase (pal), aspartate aminotransferase (ast), and pathogenesis-related protein ( $p r 1)$ were cloned, and primers were designed for a qRT-PCR protocol (Table 1) to allow expression analysis. Basal levels of lox2, pal, and ast, representing the ISR signaling pathway, were lower in CR relative to ZA, under control conditions. In response to inoculation with $\mathrm{Pb}$, the expression of lox 2 and pal markedly increased in ZA, but only pal increased in CR. These results suggest the induction of the ISR signaling pathway in both cultivars, with a stronger response of ZA. 


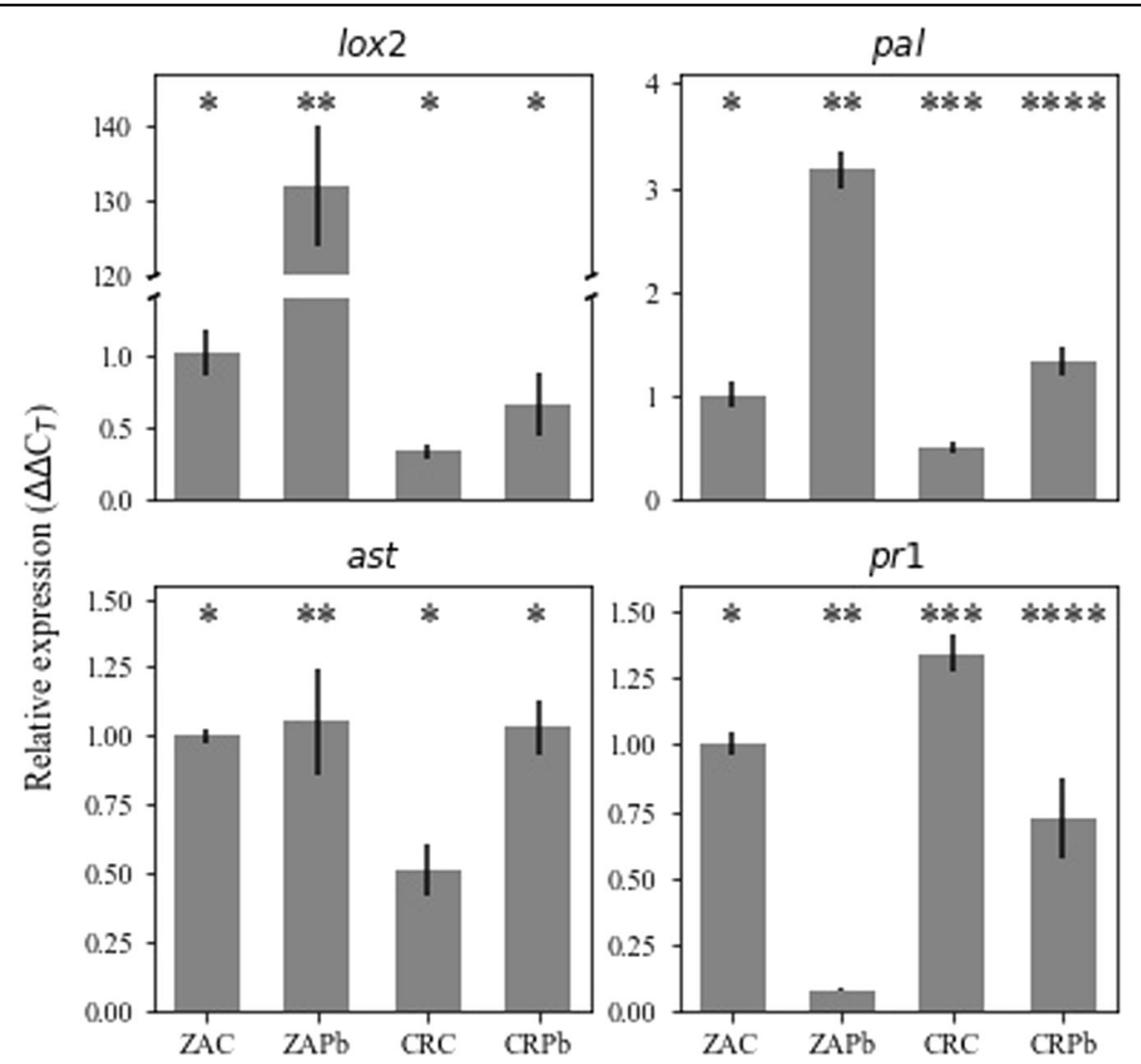

Fig. 5 Expression levels of defense-related genes in Zantedeschia aethiopica (ZA) or "Captain Romance" (CR) in response to Pectobacterium brasiliense $(\mathrm{Pb})$ inoculation. Leaf inoculation was made with $100 \mu \mathrm{l}$ of bacterial suspension $\left(10^{6} \mathrm{CFU} / \mathrm{ml}, \mathrm{OD}_{600}=0.001\right)$ or distilled water (control, C). Relative transcripts levels were determined for lox2, ast, pal, and pr1, and normalized to tubulin. Bars represent the mean relative expression \pm SD of two independent experiments with three replicates. Bars not labeled by the same mark indicate a significant difference $(P<0.05)$

The representatives of the SAR signaling pathway pr 1 were downregulated in both plants following $\mathrm{Pb}$ inoculation.

\section{Discussion}

The genus Zantedeschia is divided into two botanical sections: the section Zantedeschia with Z. aethiopica (white), being relatively tolerant to bacterial soft rot, and section Aestivae (colored hybrids) being highly susceptible $^{2,17}$. Soft rot in the genus Zantedeschia is caused mainly by Pectobacterium spp. through all phases of field production and storage ${ }^{20}$. We hypothesized that differences in the response of the two Zantedeschia groups to Pectobacterium infection may illuminate traits that are associated with higher resistance to the bacterium. Previous studies have characterized Zantedeschia accessions with relatively higher resistance to $P$. carotovorum $^{16,17,21}$, suggesting a genetic background for soft rot resistance based on heredity patterns. The traits underlining these patterns remain unclear ${ }^{2}$. Using $P$. brasiliense $(\mathrm{Pb})$, an emerging soft rot agent in warmer climate regions in potato and ornamentals ${ }^{22}$, our results confirmed earlier studies with $P$. carotovorum (formerly Erwinia carotovora subsp. carotovora) showing that colored Aestivae hybrids (FG, CR, and HS) are more susceptible to $\mathrm{Pb}$ infection than ZA, as they all developed typical soft rot disease symptoms with large necrotic areas ${ }^{2,4,17}$.

The plant canopy is a major factor in environmental survival, establishment, and spread of bacterial diseases. Accordingly, we have focused on leaf architecture, which is the first layer for bacterial attachment, colonization, and penetration. Transverse sections of leaves and petioles allowed the characterization of the in-planta environment. Surprisingly, major differences in leaf surface textures between the two Zantedeschia groups were observed. The smoother, less complex architecture abaxial surface of ZA differed significantly from that of CR (and other colored hybrids). On the other hand, transverse sections displayed larger air spaces occupying more parenchyma space in ZA compared to the more compact tissue of CR. Even more pronounced is the difference in the air spaces in petioles, almost twofold higher in ZA than in CR. We speculate that the differences may have resulted from ecological niche adaptations of the two botanical sections. Though 
Table 1 Primers used for defense-related genes expression assay

\begin{tabular}{|c|c|c|}
\hline \multicolumn{3}{|l|}{ A } \\
\hline Gene name & Primers $\left(5^{\prime} \rightarrow 3^{\prime}\right)$ & Estimated product size \\
\hline \multirow[t]{2}{*}{ Lipoxygenase 2 (lox2) } & F: CAA TGA CTT GGG TAA TCC AGA & \multirow[t]{2}{*}{950} \\
\hline & R: CAT GAG TTC TCA ACC AGT GG & \\
\hline \multirow[t]{2}{*}{ Phenylalanine ammonia lyase (pal) } & F: ATC AAC ACC CTC CTC CAG GGG TA & \multirow[t]{2}{*}{670} \\
\hline & R: CGG GTT GTC GTT CAC GGA GTT GA & \\
\hline \multirow[t]{2}{*}{ Aspartate aminotransferase (ast) } & F: GTG CCC ACA ACC CTA CTG G & \multirow[t]{2}{*}{410} \\
\hline & R: CAG CCA TGC CCT TCA GCT C & \\
\hline \multirow[t]{2}{*}{ Pathogenesis-related protein ( $p r 1)$} & F: AAA GCT CAA GAT AGC CCA CAA G & \multirow[t]{2}{*}{410} \\
\hline & R: GGC TTC TCG TTC ACA TAA TTC C & \\
\hline \multicolumn{3}{|l|}{ B } \\
\hline Gene name & Primers $\left(5^{\prime} \rightarrow 3^{\prime}\right)$ & Product size \\
\hline \multirow[t]{2}{*}{ Lipoxygenase 2 (lox2) } & F: CAT CAA GCT GCC AAG AGG TT & \multirow[t]{2}{*}{118} \\
\hline & R: GCA ACC AAG AAA ATC CGT CT & \\
\hline \multirow[t]{2}{*}{ Phenylalanine ammonia lyase (pal) } & F: GAC CTC GTC CCG CTC TCC TAC A & \multirow[t]{2}{*}{96} \\
\hline & R: CTC CAC AGC AGA GAC GTG GTG AC & \\
\hline \multirow[t]{2}{*}{ Aspartate aminotransferase (ast) } & F: GCC AGT GGT GAT CCT GAG AG & \multirow[t]{2}{*}{133} \\
\hline & R: GGA TGC TGA GGC AAC CTA CT & \\
\hline \multirow[t]{2}{*}{ Pathogenesis-related protein (pr1) } & F: GGT AGA ACC TCT TCT GGG GAT G & \multirow[t]{2}{*}{99} \\
\hline & R: AGT TGC TTC GGT AGT CGT AGT AC & \\
\hline \multirow[t]{2}{*}{ Actin } & F: GAC TCA AAT CAT GTT AGA GAC ATT CAA & \multirow[t]{2}{*}{114} \\
\hline & R: GTA CGG CCA CTG GCA TAG A & \\
\hline
\end{tabular}

(A) Primers used for sequencing of conserved sites of defense-related genes. Primers were designed based on the alignment of cDNA sequences of the monocot species Zea mays, Triticum aestivum, Oryza sativa, and of the dicot model plant Arabidopsis thaliana. (B) Primers used for qRT-PCR

both originated from southern Africa (Cape province, Lesotho, Natal, Swaziland), ZA is almost exclusively confined to the southeastern coastal belt at altitudes up to $1000 \mathrm{~m}$ of marshy wetlands; the colored Zantedeschia is restricted to the mountainous regions at altitudes of above 1200 and up to $2000 \mathrm{~m}^{1}$. The morphological features of smoother leaf surfaces and larger air spaces of the aerenchyma in leaves and petioles are part of habitat adaptation associated with wetlands and marshy valleys of lower altitude, inhabited by $\mathrm{ZA}^{23}$, while Aestivae species favor well-drained soil, with more condensed tissue and compact life form, typical of higher altitude. These features may also impact oxygen availability and possibly earlier development of anaerobic conditions during a bacterial attack. Anaerobiosis may affect oxygendependent host defenses, cell wall lignification, and suberization on the one hand, but also bacterial virulence and production of pectic enzymes on the other ${ }^{24,25}$. Larger air spaces may thus determine bacterial compatibility and contribute to higher resistance of ZA. SEM micrographs taken as soon as $3 \mathrm{~h}$ post bacterial application to the leaf surfaces showed massive colonization on the colored hybrids (CR, FG, and HS) with structures typical of bacterial group behavior. In contrast, lower cell densities with infrequent colonies were observed on ZA. Since soft rot dispersal in agricultural systems is often associated with irrigation water or aerosols ${ }^{26}$, it is obvious that leaf surfaces facing the ground have a significant impact on bacterial attachment. After successful attachment, pioneering bacteria penetrate the leaf through stomatal openings, hydathodes, or wounds, colonize the intercellular spaces, and move forward to other tissues through the vascular system ${ }^{3,13,27}$. To independently study the effect of leaf architecture on bacterial attachment and colonization, an artificial polymer replica of leaf surfaces was constructed by PDMS. Colonization patterns were recorded $4 \mathrm{~h}$ post bacterial application to the artificial surface. The results revealed comparable patterns to those observed on true leaf surfaces. The effects of surface architecture on the formation of biofilms have been 
previously reported, using artificial nanostructure features $^{28}$. Surface topography also affected biofilm development when the mesoscale-patterned polymer was used, influencing species colonization, growth, and persistence when exposed to antibiotics ${ }^{29}$. Here, leaf architecture was at least in part responsible for providing better conditions to Pectobacterium establishment on the colored Zantedeschia as observed by the formation of submicrometerscale appendages similar to those observed in E. coli during cell adhesion and biofilm formation ${ }^{30}$. Other factors that influence leaf susceptibility/tolerance to soft rot have been previously shown to involve antimicrobial compounds, as well as innate or induced defense mechanisms $^{14,31,32}$. Defenses against Pectobacterium spp. involve both SAR and ISR signaling pathways ${ }^{19}$. Here, limited fluorescence of GFP-labeled $\mathrm{Pb}+$ cells was observed on ZA following infection, which was accompanied by the accumulation of phenolic compounds around the penetration site (observed under UV filter). The accumulation of phenolic compounds around the inoculation site could be a part of the plant defense respons $^{33}$. The antimicrobial properties of phenolic compounds $^{34,35}$ could have resulted in restricted growth in ZA. Phenolic accumulation in ZA co-occurred with higher activity of PPO, the enzyme that oxidizes phenolics to quinones, which are suggested to be involved in plant defense against microbial pathogens ${ }^{36}$. Expression of defense-related genes lipoxygenase 2 (lox2), aspartate aminotransferase (ast), pathogenesis-related protein ( $p r 1)$, and phenylalanine ammonia lyase ( $p a l)$ was studied. lox2 encodes a key enzyme in the biosynthesis of the defensesignaling hormone jasmonic acid and is a representative of the ISR pathway in plants ${ }^{37}$. The largest increase in its expression was observed in $\mathrm{ZA}$ following $\mathrm{Pb}$ inoculation, which supports the induction of ISR signaling pathway in this section. ast is a regulator of carbon-nitrogen metabolism and amino acid synthesis during plant defense response to necrotrophs ${ }^{38}$. Higher expression of ast in Arabidopsis was correlated with increased sensitivity to Botrytis cinera ${ }^{39}$. Here, ast expression was upregulated in $\mathrm{CR}$ response to $\mathrm{Pb}$ infection, while in $\mathrm{ZA}$, its expression was unchanged upon bacterial infection. Similarly, expression of $p r 1$, the most recognized marker of $\mathrm{SAR}^{40}$, was downregulated in both Zantedeschia cultivars in response to $\mathrm{Pb}$ inoculation, supporting previous reports showing that SAR is less efficient in resistance to Pectobacterium spp $^{14,33}$. Finally, pal expression is recognized as the first committed step in the phenylpropanoid pathway, leading to the synthesis of phenolic compounds. Expression levels of this gene were increased in both Zantedeschia sections, with a stronger response in ZA, confirming its involvement in resistance to Pectobacterium $\mathrm{spp}^{36}$. This observation fits with the accumulation of phenolic compounds around the infection site in ZA.
In conclusion, the involvement of less explored aspects of host-plant interactions with the soft rot bacterium $\mathrm{Pb}$ was demonstrated. The emphasis on plant morphological features and environmental adaptations revealed higher resistance of Zantedeschia section to Pectobacterium spp. infection. This resistance mechanism is a multifaceted phenomenon that involves several factors of which surface area architectures and tissue compactness play a role in addition to differential induced defense responses following pathogen infection.

\section{Materials and methods}

\section{Plant material, bacterial strains, and growth conditions}

Commercially grown calla lily plants: white calla lily (Zantedeschia aetheopica) ZA and colored calla lily hybrids ("Captain Romance", CR; "Florex Gold", FG; "Hot Shot", HS) were grown in a greenhouse $\left(25 / 10^{\circ} \mathrm{C}\right.$ maximum/minimum, natural daylight). The youngest fully spread leaf was cut at the base of the petiole and used fresh for all analyses. $\mathrm{Pb}$ isolated from potato and the same strain carrying green fluorescence protein-GFP $(\mathrm{Pb}+)$ were used in the study. The strains were cultured at $28^{\circ} \mathrm{C}$ in Luria-Bertani (LB) medium (Difco Laboratories, MI, USA), supplemented with ampicillin $100 \mu \mathrm{g} / \mathrm{ml}$ for $\mathrm{Pb}+$, under continuous shaking of $200 \mathrm{rpm}$. P. brasiliense has a broad temperature range $-20-39^{\circ} \mathrm{C}$ with optimum at $31-32{ }^{\circ} \mathrm{C}^{9}$. In all, $28^{\circ} \mathrm{C}$ is a suboptimal temperature for $P$. brasiliense and was chosen to avoid drastic temperature change to the plants grown at $25^{\circ} \mathrm{C}$ and to slow down the rapid response of the highly sensitive colored hybrids.

\section{Screening for resistance to soft rot infection}

Leaf discs excised from different calla lily cultivars were prepared as previously described ${ }^{14}$, kept on half-strength Murashige and Skoog (MS) minimal medium, and challenged with $10 \mu \mathrm{l}$ of bacterial suspension $\left(10^{8} \mathrm{CFU} / \mathrm{ml}\right.$, $\left.\mathrm{OD}_{600}=0.1\right)$ of $\mathrm{Pb}$ or distilled water as a control. The inoculated plant material was incubated at $28^{\circ} \mathrm{C}$. Disease progress was evaluated $24 \mathrm{~h}$ post inoculation, as the percentage of tissue decay relative to the total area of the leaf disc. The decayed area was measured using the Threshold_Colour plugin of the imageJ software $(\mathrm{NIH}, \mathrm{MD}$, USA). Three independent experiments were carried out, each using four leaves, with 10 replicates, 40 leaf discs per treatment $(\mathrm{Pb} /$ control for every cultivar). Fluorescence microscopy observations of the inoculated leaf discs were conducted as previously described ${ }^{33}$.

\section{Microscopic examination}

Transverse hand sections cut from the petiole were put in distilled water and stained with toluidine blue as described by Villodron ${ }^{41}$. Also, leaf sections were prepared as explained by Ruzin et al. ${ }^{42}$. In brief, small pieces 
of leaves were fixed with FAA (formalin: glacial acetic acid:ethyl alcohol: 5:5:90). Fixation was followed by an ethanol dilution series and subsequent stepwise exchange of ethanol with 'Histoclear' (xylem substitute, National Diagnostics GA, USA). Samples were then embedded in paraffin and cut with an RM2245 microtome (Leica Biosystems, Germany) into $20-\mu \mathrm{m}$ thick sections. Furthermore, sections were stained using safranin-fast green and examined with a Leica DMLB microscope (Leica Microsystems, Germany) to observe the tissue morphology. The microscope was equipped with a DS-Fil camera (Nikon Instruments Inc., Japan).

SEM observations of the leaf surface and attachment of the bacteria to the abaxial leaf surface of different cultivars were studied $3 \mathrm{~h}$ post application of $10 \mu \mathrm{l}$ of bacterial suspension $\left(10^{8} \mathrm{CFU} / \mathrm{ml}, \mathrm{OD}_{600}=0.1\right)$ onto the leaf surface. The leaves were allowed to dry for $3 \mathrm{~h}$ before fixation of the samples in $70 \%$ ethanol overnight, followed by dehydration with $90 \%, 95 \%$, and $100 \%$ ethanol, each for an hour. Finally, samples were dried on K850 critical point dried and coated with gold-palladium alloy on mini sputter coater, following the manufacturer's instructions (Quorum Technology Ltd., UK). The samples were observed under SEM, Jeol JSM 5410 (JEOL Inc, MA, USA). Leaves for SEM were taken from three different plants of each cultivar, with ten replicates each. Images are representative of bacterial colonization patterns on each of the calla lily cultivars/hybrids.

\section{PDMS-BPS surface fabrication}

Polydimethylsiloxane (PDMS) prepolymer and curing agent from Sylgard ${ }^{\mathrm{TM}} 184$ silicone elastomer kit (The Dow Chemical Company, MI, USA) were mixed at a ratio of $10: 1 \mathrm{w} / \mathrm{w}$, stirred thoroughly, and degassed under vacuum. A calla lily leaf was glued on a Petri dish with the abaxial side facing up. The PDMS was poured onto the leaf, vacuumed for $2 \mathrm{~h}$, and was cured on the bench at room temperature overnight. The next day, the PDMS layer, known as the negative replica, was gently peeled off from the leaf. The negative replica was activated by exposure to plasma torch BD-20ACV, High-Frequency Generator (Electro-Technic Products, IL, USA) for $30 \mathrm{~s}$. The negative replica was then placed in a desiccator with $100 \mu \mathrm{l}$ of Trichloro $(1 \mathrm{H}, 1 \mathrm{H}, 2 \mathrm{H}, 2 \mathrm{H}$-perfluoro-octyl) silane (SigmaAldrich, MO, USA) and subjected to vacuum for $3 \mathrm{~h}$. After activation, a mixture of PDMS and curing agent (10:1) was poured over a negative replica. The negative and the liquid polymer were placed under vacuum for $2 \mathrm{~h}$ followed by curing at RT overnight. The newly formed polymer layer, known as the positive replica, was gently separated from the negative replica and was later used for bacteria colonization assay and visualization. Three PDMS-positive replicas of both ZA and CR leaves were used for SEM study, $4 \mathrm{~h}$ post inoculation with $10 \mu \mathrm{l}$ of bacterial suspension $\left(10^{8} \mathrm{CFU} / \mathrm{ml}, \mathrm{OD}_{600}=0.1\right)$. The experiment was repeated twice.

\section{Luminescence and fluorescence imaging}

To visualize in situ reaction $24 \mathrm{~h}$ post inoculation with $\mathrm{Pb}+(\mathrm{Pb}$ labeled with GFP), leaf samples were examined under a Leica MZFLIII stereomicroscope (Leica Microsystems, Germany) equipped with a DS-Fi1 camera (Nikon, NY, USA) and NIS-Elements (Nikon, NY, USA) software (ver. 3.06). GFP was excited with 440-520-nm light and emission was detected through a $520-600-\mathrm{nm}$ GFP2 filter. To observe phenolic compounds' autofluorescence, 320-400-nm lasers were used for excitation, and emission was assessed through a UV filter at $420 \mathrm{~nm}$.

\section{Total RNA extraction and CDNA preparation}

The total RNA was isolated from leaf segments of control and infected ZA or CR leaves, using RNA buffer (10 mM Tris- $\mathrm{HCl}, \mathrm{pH} 8.0 ; 1 \mathrm{mM} \mathrm{LiCl}, 0.2 \mathrm{mM}$ EDTA, and $1 \%$ LiDS) and hot phenol. For each cultivar, three biological replications were made per treatment, each with three replicates. Leaves were infiltrated with $100-\mu \mathrm{l}$ bacterial suspension $\left(10^{6} \mathrm{CFU} / \mathrm{ml}, \mathrm{OD}_{600}=0.001\right)$, applied to four spots on each leaf. Leaf tissue, 200-mg segments, $24 \mathrm{~h}$ after inoculation with $\mathrm{Pb}$, were ground to a fine powder by mixer mill tissuelyser (Retch, Germany) under liquid nitrogen. RNA was extracted and cDNA was prepared as previously reported ${ }^{43}$.

\section{Primer design and quantitative reverse transcriptase qRT-PCR}

The whole-genome sequence of calla lily is not available; thus, cDNA sequences of the monocot species Zea mays, Triticum aestivum, Oryza sativa, and of the dicot model plant Arabidopsis thaliana were aligned to identify the conserved sites across all species. Primers were designed, based on these conserved sites, and PCR was performed on the cDNA of the calla lily plant tissues (Table 1). PCR products were then sequenced in a 3730 DNA analyzer (Applied Biosystems, CA, USA) to obtain cDNA sequences of specific genes in calla lily (Zantedeschia sp.). These were further used to design primers for qRT-PCR (Table 1) to quantify the expression of defense-related genes in this study. PCR products of the latter primers were cloned into a pGEM-T vector using pGEM $^{\circledR}$-T Easy Vector System kit (Promega, WI, USA). In all, $2 \mu \mathrm{l}$ of PCR product was mixed with $50 \mu \mathrm{l}$ of competent E. coli (TOP10) $\mathrm{DH} 5 \alpha$ on ice, then a heat shock protocol was applied at $42^{\circ} \mathrm{C}$ for $45 \mathrm{~s}$ followed by ice. The cells were incubated on a rotary shaker for $1 \mathrm{~h}$ at $37^{\circ} \mathrm{C}$ and then plated on a selective medium containing $100 \mu \mathrm{g} \mathrm{ml}^{-1}$ ampicillin, and additional $100 \mu \mathrm{l}$ of isopropyl $\beta$-D-1-thiogalactopyranoside (IPTG) $0.1 \mathrm{M}$ and $20 \mu \mathrm{l}$ of 5bromo-4-chloro-indolyl- $\beta$-D-galactopyranoside (X-GAL) 
$0.5 \mathrm{~g} \mathrm{ml}^{-1}$ for a blue-white screen. Transformed colonies were grown overnight with LB supplemented with $100 \mu \mathrm{g}$ $\mathrm{ml}^{-1}$ ampicillin and plasmid DNA was extracted with PureYield ${ }^{\mathrm{TM}}$ Plasmid Miniprep System (Promega, Madison, WI, USA) and sequenced for validation using the T7 primer 5'-TAATACGACTCACTATAGGG- ${ }^{\prime 44}$.

The SYBR ${ }^{\circledR}$ Green (Applied Biosystems, USA) qRTPCR assay was used to determine the expression of defense-related genes in ZA and CR following challenge infection with $\mathrm{Pb}$. Real-time PCR amplifications were performed in Step One Plus real-time PCR system (Applied Biosystems, CA, USA) using gene-specific primers (Table 1 ), as previously reported ${ }^{35}$. The data were analyzed by the comparative $C_{T}\left(\Delta \Delta C_{T}\right)$ method, with expression normalized to the expression of the reference gene actin.

\section{Data analysis}

Data were analyzed for significance using JMP software (SAS, Cary, NC, USA) by Student's $t$ test, or ANOVA with Tukey-Kramer HSD. $P<0.05$ was considered statistically significant unless specified otherwise.

\section{Acknowledgements}

This research was funded by the Chief Scientist of the Israeli Ministry of Agriculture (Grant No. 20-01-0193).

\section{Author details}

${ }^{1}$ The Robert H. Smith Faculty of Agriculture, Food and Environment, The Hebrew University of Jerusalem, Rehovot, Israel. ${ }^{2}$ Institute of Plant Sciences, Agricultural Research Organization, Volcani Center, Rishon Lezion, Israel. ${ }^{3}$ Department of Horticulture and Landscape Architecture, Colorado State University, Fort Collins, CO, USA

\section{Author contributions}

Y.G., J.R.J., N.K., and N.R. conducted experiments, analyzed the data, and prepared the paper. N.T. and Z.W. conducted experiments and analyzed microscopic data. M.K., Z.K., and I.Y. coordinated the experiments, data analysis, and wrote the paper.

\section{Data availability}

The dataset of gene fragments sequenced in this study is available at figshare. com (https://doi.org/10.6084/m9.figshare.12326495).

\section{Conflict of interest}

The authors declare that the research was conducted in the absence of any commercial or financial relationships that could be construed as a potential conflict of interest.

Supplementary Information accompanies this paper at (https://doi.org/ 10.1038/s41438-020-00446-2).

Received: 6 September 2020 Revised: 7 November 2020 Accepted: 13 November 2020

Published online: 01 January 2021

\section{References}

1. Funnell, K. A. 'Zantedeschia'. In The Physiology of Flower Bulbs (eds. De Hertogh, A., \& Le Nard, M.) 683-704. Elsevier, 1993.

2. Snijder, R. C., Cho, H.-R., Hendriks, M. M. W. B., Lindhout, P. \& van Tuyl, J. M. Genetic variation in Zantedeschia spp. (Araceae) for resistance to soft rot caused by Erwinia carotovora subsp. carotovora. Euphytica 135, 119-128 (2004).

3. Singh, U. S., Singh, R. P. \& Kohmoto, K. Pathogenesis and Host Specificity in Plant Diseases: Histopathological, Biochemical, Genetic, and Molecular Bases. Pergamon, 1995.

4. Wei, Z. et al. Assessing genetic diversity and population differentiation of colored Calla Lily (Zantedeschia Hybrid) for an efficient breeding program. Genes 8, 168 (2017).

5. Hu, W.-C., Huang, C.-H., Lee, S.-C., Wu, C.-I. \& Chang, Y.-C. Detection of four calla potyviruses by multiplex RT-PCR using nad5 mRNA as an internal control. Eur. J. Plant Pathol. 126, 43 (2009).

6. Ma, B. et al. Host range and molecular phylogenies of the soft rot enterobacterial genera Pectobacterium and Dickeya. Phytopathology ${ }^{\mathrm{TM}}$ 97, 1150-1163 (2007).

7. Yishay, M. et al. Differential pathogenicity and genetic diversity among Pectobacterium carotovorum ssp. carotovorum isolates from monocot and dicot hosts support early genomic divergence within this taxon. Environ. Microbiol. 10, 2746-2759 (2008)

8. Charkowski, A. O. The changing face of bacterial soft-rot diseases. Annu. Rev. Phytopathol. 56, 269-288 (2018).

9. du Raan, S., Coutinho, T. A. \& van der Waals, J. E. Cardinal temperature differences, determined in vitro, between closely related species and subspecies of pectinolytic bacteria responsible for blackleg and soft rot on potatoes. Eur. J. Plant Pathol. 144, 361-369 (2016).

10. Toth, I. K., Bell, K. S., Holeva, M. C. \& Birch, P. R. J. Soft rot erwiniae: from genes to genomes. Mol. Plant Pathol. 4, 17-30 (2003).

11. Charkowski, A. O. The soft rot Erwinia. In Plant-Associated Bacteria (ed. Gnanamanickam, S. S.) 423-505 (Springer Netherlands, 2006).

12. Czajkowski, R., Pérombelon, M. C. M., Veen, J. Avan \& Wolf, J. Mvander. Control of blackleg and tuber soft rot of potato caused by Pectobacterium and Dickeya species: a review. Plant Pathol. 60, 999-1013 (2011).

13. Kubheka, G. C., Coutinho, T. A., Moleleki, N. \& Moleleki, L. N. Colonization patterns of an mCherry-tagged Pectobacterium carotovorum subsp. brasiliense strain in potato plants. Phytopathology 103, 1268-1279 (2013).

14. Luzzatto, T. et al. Efficient, long-lasting resistance against the soft rot bacterium Pectobacterium carotovorum in calla lily provided by the plant activator methyl jasmonate. Plant Pathol. 56, 692-701 (2007).

15. De Boer, S. H. Characterization of pectolytic Erwinias as Highly sophisticated pathogens of plants. Eur. J. Plant Pathol. 109, 893-899 (2003).

16. Snijder, R. C., Brown, F. S. \& van Tuyl, J. M. The role of plastome-genome incompatibility and biparental plastid inheritance in interspecific hybridization in the Genus Zantedeschia (Araceae). Floriculture Ornamental Biotechnol. 8, 150-157 (2007).

17. Snijder, R. C. \& van Tuyl, J. M. Evaluation of tests to determine resistance of Zantedeschia spp. (Araceae) to soft rot caused by Erwinia carotovora subsp. carotovora. Eur. J. Plant Pathol. 108, 565-571 (2002).

18. Yao, J.-L., Cohen, D. \& Rowland, R. E. Plastid DNA inheritance and plastomegenome incompatibility in interspecific hybrids of Zantedeschia (Araceae). Theor. Appl. Genet. 88, 255-260 (1994).

19. Davidsson, P. R., Kariola, T., Niemi, O. \& Palva, E. T. Pathogenicity of and plant immunity to soft rot pectobacteria. Front. Plant Sci. 4, 191 (2013).

20. Wright, P. J., Burge, G. K. \& Triggs, C. M. Effects of cessation of irrigation and time of lifting of tubers on bacterial soft rot of calla (Zantedeschia spp.) tubers. N.Z. J. Crop Horticultural Sci. 30, 265-272 (2002).

21. Cho, H. R. et al. Virulence variation in 20 isolation of Erwinia carotovora subsp. carotovora on Zantedeschia cultivars in Korea. Acta Horticu. 653-659. https:// doi.org/10.17660/ActaHortic.2005.673.90 (2005).

22. Wolf, J. Mvander et al. Virulence of Pectobacterium carotovorum subsp. brasiliense on potato compared with that of other Pectobacterium and Dickeya species under climatic conditions prevailing in the Netherlands. Plant Pathol. 66, 571-583 (2017).

23. Cutler, D. F., Botha, T. \& Stevenson, D., Wm. Adaptive features. In Plant Anatomy: An Applied Approach (Blackwell publishing Ltd, 2008).

24. Maher, E. \& Kelman, A. Oxygen status of potato tuber tissue in relation to maceration by pectic enzymes of Enwinia carotovora. Phytopathology 73, 536-539 (1983).

25. Babujee, L. et al. Evolution of the metabolic and regulatory networks associated with oxygen availability in two phytopathogenic enterobacteria. BMC Genomics 13, 110 (2012).

26. Perombelon, M. C. M. \& Kelman, A. Ecology of the soft rot Erwinias. Annu. Rev. Phytopathol. 18, 361-387 (1980). 
27. Pérombelon, M. C. M. Potato diseases caused by soft rot erwinias: an overview of pathogenesis. Plant Pathol. 51, 1-12 (2002).

28. Hochbaum, A. I. \& Aizenberg, J. Bacteria pattern spontaneously on periodic nanostructure arrays. Nano Lett. 10, 3717-3721 (2010).

29. Bhattacharjee, A., Khan, M., Kleiman, M. \& Hochbaum, A. I. Effects of growth surface topography on bacterial signaling in coculture biofilms. ACS Appl. Mater. Interfaces 9, 18531-18539 (2017).

30. El Abed, S., Ibnsouda, S.K., Latrache, H. \& Hamadi, F. Scanning electron microscopy (SEM) and environmental SEM: suitable tools for study of adhesion stage and biofilm formation. In Scanning Electron Microscopy (ed. Kazmiruk, V.) IntechOpen, 2012.

31. Luzzatto-Knaan, T., Kerem, Z., Lipsky, A. \& Yedidia, I. A systemic response of geophytes is demonstrated by patterns of protein expression and the accumulation of signal molecules in Zantedeschia aethiopica. Plant Physiol. Biochem. 71, 218-225 (2013).

32. Wegener, C. B. \& Jansen, G. Soft-rot resistance of coloured potato cultivars (Solanum tuberosum L.): the role of anthocyanins. Potato Res. 50, 31-44 (2007).

33. Luzzatto, T. et al. Priming of antimicrobial phenolics during induced resistance response towards Pectobacterium carotovorum in the ornamental monocot Calla Lily. J. Agric. Food Chem. 55, 10315-10322 (2007).

34. Joshi, J. R., Burdman, S., Lipsky, A. \& Yedidia, I. Effects of plant antimicrobial phenolic compounds on virulence of the genus Pectobacterium. Res. Microbiol. 166, 535-545 (2015).

35. Joshi, J. R., Burdman, S., Lipsky, A., Yariv, S. \& Yedidia, I. Plant phenolic acids affect the virulence of Pectobacterium aroidearum and P. carotovorum ssp. brasiliense via quorum sensing regulation. Mol. Plant Pathol. 17, 487-500 (2016).
36. Ngadze, E., Icishahayo, D., Coutinho, T. A. \& van der Waals, J. E. Role of polyphenol oxidase, peroxidase, phenylalanine ammonia lyase, chlorogenic acid, and total soluble phenols in resistance of potatoes to soft rot. Plant Dis. 96, 186-192 (2012).

37. Yan, $L$. et al. Role of tomato lipoxygenase $D$ in wound-induced jasmonate biosynthesis and plant immunity to insect herbivores. PLoS Genet. 9, e1003964 (2013).

38. Zhou, Y. et al. Over-expression of aspartate aminotransferase genes in rice resulted in altered nitrogen metabolism and increased amino acid content in seeds. Theor. Appl. Genet. 118, 1381-1390 (2009).

39. Brauc, S., De Vooght, E., Claeys, M., Höfte, M. \& Angenon, G. Influence of overexpression of cytosolic aspartate aminotransferase on amino acid metabolism and defence responses against Botrytis cinerea infection in Arabidopsis thaliana. J. Plant Physiol. 168, 1813-1819 (2011).

40. Kiefer, I. W. \& Slusarenko, A. J. The pattern of systemic acquired resistance induction within the Arabidopsis rosette in relation to the pattern of translocation. Plant Physiol. 132, 840-847 (2003).

41. Villordon, A. Q. et al. Characterization of adventitious root development in sweetpotato. HortScience 44, 651-655 (2009).

42. Ruzin, S. E. Plant Microtechnique and Microscopy, Vol. 198 (Oxford University Press New York, 1999).

43. Khadka, N. et al. Host specificity and differential pathogenicity of Pectobacterium strains from dicot and monocot hosts. Microorganisms 8, 1479 (2020).

44. Mead, D. A., Szczesna-Skorupa, E. \& Kemper, B. Single-stranded DNA 'blue' T7 promoter plasmids: a versatile tandem promoter system for cloning and protein engineering. Protein Eng. Des. Sel. 1, 67-74 (1986). 